\title{
Remission from Kaposi's sarcoma on HAART is associated with suppression of HIV replication and is independent of protease inhibitor therapy
}

\author{
V Martinez ${ }^{*}$, ,2, E Caumes², L Gambotti ${ }^{3}$, H Ittah ${ }^{3}$, J-P Morini', J Deleuze', I Gorin', C Katlama², F Bricaire ${ }^{2}$ and \\ N Dupin'
}

'Service de Dermatologie, Hôpital Tarnier-Cochin, AP-HP, UPRES 1833, Université Paris V 89, rue d'Assas, Paris 75006, France; ${ }^{2}$ Département des Maladies Infectieuses et Tropicales, Hôpital Pitié-Salpêtrière, AP-HP, Université Pierre et Marie Curie, 45-83, boulevard de l'hôpital, Paris 750 I 3, France;

${ }^{3}$ Département de Santé Publique, Hôpital Pitié-Salpêtrière, AP-HP, Université Pierre et Marie Curie, 45-83, boulevard de l'hôpital, Paris 750 I3, France

Highly active antiretroviral therapy (HAART) reduces the incidence and improves the prognosis of Kaposi's sarcoma (KS). This study was designed to identify factors associated with KS clinical responses in HIV-infected patients during HAART. We reviewed the files of I 38 HIV-I-infected patients with KS. Epidemiologic and HIV-related clinical and biological parameters were recorded at KS diagnosis (baseline) and every 6 months thereafter. In a subset of 73 antiretroviral-naive patients, we compared the clinical outcome of KS according to the use or nonuse of protease inhibitors (PI). After 6 months of follow-up, KS remission was more frequent in patients who were naive of HAART and who were at ACTG stage S0 at baseline ( $P=0.03$ and 0.02$)$. Undetectable HIV viral load was strongly associated with KS remission ( $P \leqslant 0.004$ at all time points), while CD4 cell count was not. Among the 73 antiretroviralnaive patients at baseline, and who were studied for 24 months, KS outcome did not differ between patients who were prescribed PIcontaining and $\mathrm{Pl}$-sparing regimens. Intercurrent multicentric Castleman's disease was associated with poor outcome after 60 months of follow-up $(P \leqslant 0.000 \mathrm{I})$. Fourteen deaths occurred after a median follow-up of 37.5 months, eight of which were KS related. Suppression of HIV replication appears to be crucial to control KS. Non-PI-based regimens were equivalent to PI-based regimens as regards the clinical and virological outcome of antiretroviral-naive HIV-infected patients with KS.

British Journal of Cancer (2006) 94, I000-1006. doi:I0.I038/sj.bjc.6603056 www.bjcancer.com

Published online 28 March 2006

(C) 2006 Cancer Research UK

Keywords: Kaposi's sarcoma; HIV; HAART; naive patients; viral load; CD4 cell counts

Kaposi's sarcoma (KS) has remained the most common AIDSassociated malignancy since the beginning of the HIV/AIDS pandemic (Brodt et al, 1997). The introduction of highly active antiretroviral therapy (HAART) in 1996 was associated with undetectable HIV plasma viral load in most patients, together with increased CD4 cell counts, increased survival, and fewer opportunistic infections and AIDS-associated malignancies (Li et al, 1998; Palella et al, 1998; Levine and Tulpule, 2001). Most studies have shown that KS improves during protease inhibitor (PI)-based antiretroviral treatment, an effect variously attributed to modulation of Tat and of production of HIV cytokines, restoration of specific anti-human herpesvirus type $8(\mathrm{HHV}-8)$ immunity, or the

\footnotetext{
*Correspondence: Dr V Martinez Département des Maladies Infectieuses et Tropicales, Hôpital Pitié-Salpêtrière, AP-HP, Université Pierre et Marie Curie, 45-83, boulevard de l'hôpital, Paris 750I3, France; E-mail: valerie.martinez@psl.ap-hop-paris.fr

This work was presented at the II th Conference on Retroviruses and Opportunistic Infections (CROI), 8- II February, 2004, San Francisco, CA, USA. Poster Abstracts: 779.

Received 12 September 2005; revised 22 February 2006; accepted 22 February 2006; published online 28 March 2006
}

antiangiogenic and antiproliferative effect of PIs (Krischer et al, 1998; Lebbe et al, 1998; Cattelan et al, 1999, 2001; Paparizos et al, 2002; Leitch et al, 2003). The impact of HAART on immune responses to HHV-8, the main aetiologic agent of KS and multicentric Castleman's disease, is poorly understood. Kaposi's sarcoma lesions are characterised by neoangiogenesis and proliferation of spindle cells of endothelial origin, including cells of lymphatic lineage (Dupin et al, 1999). Although experimental studies have shown that PI may have specific antiangiogenic and antiproliferative properties, their specific impact on the clinical outcome of KS has been discussed (Sgadari et al, 2002, 2003). Complete remission of KS has been reported in patients receiving PI, and also relapses after switching to NNRTI-based regimens (Murdaca et al, 2002; Bani-Sadr et al, 2003). In contrast, a significantly lower incidence of KS was observed in HIV-infected patients receiving an NNRTI-based regimen than in those receiving a PI-based regimen in a cohort of 8640 patients (Portsmouth et al, 2003). Moreover, NNRTI are also as effective as PIs in prolonging time to treatment failure in KS (Bower et al, 1999).

The antiangiogenic action of PI makes these drugs the treatment of choice for HIV-infected patients with KS. However, the so-called $\mathrm{PI}$-sparing regimens are equivalent to PI-based regimens as 
regards HIV control, while they have better observance and fewer adverse effects (Bucher et al, 2003). In order to compare the impact of PI-based and non-PI-based antiretroviral regimens on KS, we reviewed the epidemiological and clinical characteristics and outcome of 138 HIV-1-infected, HAART-treated patients with KS. We also sought factors predictive with KS progression during HAART, analysed the outcome of KS according to CD4 cell count and HIV-1 plasma viral load variations, and compared the benefits of PI and non-PI-based regimens on KS in a subgroup of patients who had not previously received antiretroviral drugs.

\section{PATIENTS AND METHODS}

This retrospective study was conducted in the Department of Infectious Diseases and the Department of Dermatology of two hospitals in Paris, France. Patients were eligible for the study if they had HIV-1 infection and KS, and received HAART before or at the time of KS diagnosis. The time of KS diagnosis was considered as coming on study. Kaposi's sarcoma had to be diagnosed between January 1996 (corresponding to widespread introduction of HAART in France) and May 2001. Protease inhibitor drugs were available in France since January 1996 whereas regimen with NNRTI since 1998. According to their respective availability and international recommandations, triple NRTI or NNRTI-based therapy were thus more likely to be recently prescribed than PI-based therapy. Patients with other neoplasms and those with HHV-8 disease diagnosed before January 1996 were not eligible for the study. The following epidemiological and clinical data were recorded at the time of KS diagnosis (baseline): age, gender, HIV risk group, known duration of HIV infection, the ACTG stage of KS (Krown et al, 1997), specific chemotherapy for $\mathrm{KS}$, and associated multicentric Castleman disease. Central, east, west Africa, southern Italy and south America were considered as endemic countries for HHV-8 infection. The occurrence of opportunistic infections or death, and immunologic and virologic parameters of HIV infection (CD4 cell count and HIV-1 plasma viral load) were recorded at baseline and at 6-month intervals throughout follow-up, for outcome of HHV-8-associated malignancies too. HIV plasma viral load was considered undetectable if below 200 copies per millilitre. Specific cytotoxic therapy for KS was used in a part of the patients and included: combination of doxorubicin, daunorubicin, bleomycin, vinblastine, liposomal anthracycline or paclitaxel, monotherapy of bleomycin or vinblastine, IFN-alpha, beta-HCG or local therapy.

In a subgroup of 73 patients who were antiretroviral naive at baseline, we compared the outcome of KS according to the use or non use of PI. Patients were treated and evaluated every 6 months until 24 months under the same combination of antiretroviral drugs. The choice of HAART was left to the patients' individual physicians. 'KS remission' refers to partial or complete remission as defined in ACTG study (Krown et al, 1997), and 'KS progression' refers to stable disease, progressive lesions or death related to KS.

The patient's characteristics were recorded as counts or percentages for categorical variables, and medians and ranges for continuous variables. Categorical variables were compared between patients by using the $\chi^{2}$ test or Fisher's exact test, as appropriate. Continuous variables were compared using MannWhitney test. Differences between groups were considered significant if $P \leqslant 0.05$. A multivariate logistic regression model was used to identify independent predictive factor for $\mathrm{KS}$ remission at 6 months by including in the model all the variables which were statistically significant or tended to be in univariate analysis $(P<0.1)$. Statistical analysis used the SPSS 11.5 program (Chicago, IL, USA).

\section{RESULTS}

\section{Baseline characteristics of the patients}

We selected and included in this study 138 HIV-1-infected patients from the clinical databases of the two participating units with KS, including five with multicentric Castleman's disease. The baseline characteristics of the 138 patients are shown in Table 1. Median age was 44 years (range 27-73 years). They were 135 men, of whom 101 were homosexual. Kaposi's sarcoma was the first AIDSdefining disease in 43 patients. The 95 other patients were defined as having AIDS according to the CDC classification, before the diagnosis of KS. Thirty-seven patients had already had one or more AIDS-defining events at the onset of KS (nine cytomegalovirus infection, nine atypical mycobacteriosis, eight cerebral toxoplasmosis, five pneumocystosis, six herpes simplex virus infection, three tuberculosis, three non-Hodgkin's lymphoma, two cryptococcosis and one multifocal progressive leukoencephalitis). Forty-one $(29.7 \%)$ patients originated from a country where HHV8 is endemic.

At KS diagnosis the median CD4 cell count was $68 \mathrm{~mm}^{-3}$ (range 0 -797) and the median HIV-1 viral load was 176000 copies ml $^{-1}$ (range 199-2 831000) in the whole group. The ACTG stages were predominantly T0, I1 and S1. Sixty-five patients were already receiving HAART and 73 patients had never received antiretroviral therapy when KS was diagnosed but began HAART at this time. In the subgroup of naive patients, the median CD4 cell count was $72 \mathrm{~mm}^{-3}$ (range 0-797) and the median HIV-1 viral load was 225235 copies $\mathrm{ml}^{-1}$ (range 3870-2831000) whereas in patients

Table I Baseline characteristics of the $138 \mathrm{HIV}$-infected patients with Kaposi's sarcoma

\begin{tabular}{|c|c|c|}
\hline Baseline characteristics & Number of patients & $\%$ \\
\hline \multicolumn{3}{|l|}{ Gender } \\
\hline Male & 135 & 97.8 \\
\hline Female & 3 & 2.2 \\
\hline Multicentric Castleman's disease & 5 & 3.6 \\
\hline Patients from HHV-8-endemic countries & 41 & 29.7 \\
\hline \multicolumn{3}{|l|}{ HIV exposure group } \\
\hline Homosexual & 101 & 73.2 \\
\hline Heterosexual & 33 & 23.9 \\
\hline Intravenous drug users & 4 & 2.9 \\
\hline \multicolumn{3}{|l|}{ ACTG TIS classification } \\
\hline & 79 & 57.2 \\
\hline T0 & 59 & 42.8 \\
\hline $\mathrm{TI}$ & 37 & 26.8 \\
\hline 10 & 101 & 73.2 \\
\hline 11 & 49 & 35.5 \\
\hline so & 89 & 64.5 \\
\hline \multicolumn{3}{|l|}{ SI } \\
\hline AIDS before KS diagnosis & 95 & 68.8 \\
\hline Opportunistic infections at KS diagnosis & 37 & 26.8 \\
\hline \multicolumn{3}{|l|}{ Ongoing HAART at KS diagnosis } \\
\hline Yes & 65 & 47.1 \\
\hline \multirow[t]{2}{*}{ No } & 73 & 52.9 \\
\hline & Median & Range \\
\hline Age (years) & 44 & $27-73$ \\
\hline CD4 cell counts (per mm m $^{3}$ & 68 & $0-797$ \\
\hline HIV viral load (copies ml $\left.{ }^{-1}\right)^{\mathrm{a}}$ & 176000 & $199-2831000$ \\
\hline
\end{tabular}


already receiving HAART, the corresponding figures were $66 \mathrm{~mm}^{-3}$ (range 0-500) and 140000 copies $\mathrm{ml}^{-1}$ (range 199$747000)$. Plasma viral load was significantly higher $(P=0.004)$ in naive patients than in patients previously treated by HAART whereas CD4 cell counts did not differ $(P=0.88)$ between the two groups. For patients already receiving HAART regimen at KS diagnosis, the median duration of HAART was 33 weeks (range 16-98). Highly active antiretroviral therapy consisted of combinations of three NRTI $(n=17)$, or two NRTI plus one NNRTI $(n=12)$, or two NRTI plus one or two PI $(n=109)$ and was chosen by each physician.

\section{KS treatment and outcome}

Seventy-two patients with KS received specific chemotherapy including: adriamycin, bleomycin and vinblastine in 33 cases, paclitaxel in two cases, daunorubicin in two cases, other combinations of drugs in five cases, monotherapy of bleomycin in 17 cases and of vinblastine in six cases, IFN-alpha in three cases, local therapy in three cases and beta-HCG in one case for the first 6 months after diagnosis. Of the 73 naive patients, $40(55 \%)$ underwent a specific chemotherapy and 32 of the 65 (49\%) patients previously treated by HAART. The use or not of specific cytotoxic drugs for KS had no impact on the evolution of KS in patients who were already receiving antiretroviral therapy at baseline $(P=0.32)$ and in naive patients $(P=0.59$ comparing PI and non-PI-containing regimen). Nevertheless, the use of cytotoxic agents was left at the discretion of the treating physician according to the localisation and extension of the disease. Only five patients were still receiving specific therapy for KS 24 months after diagnosis. The percentage of patients in remission from KS increased during follow-up, from $51 \%$ at 6 months to $62 \%$ at 12 months, $70 \%$ at 18 months and $76 \%$ at 24 months. After a median follow-up of 37.5 months (range 6-60 months), 14 patients (10\%) had died, of HHV-8 malignancies in eight cases (four with both $\mathrm{KS}$ and multicentric Castleman's disease) and of opportunistic infections in six cases.

\section{Factors predictive of KS outcome in the HAART era}

Patients who were antiretroviral naive and those with KS stage S0 at baseline had a significantly higher chance of KS remission during the first 6 months of follow-up $(P=0.03$ and 0.02 , respectively) (Table 2 ). Moreover, in the 73 naive patients, there was a trend to KS remission for patients with stage T0 $(P=0.08)$ and stage So $(P=0.07)$. We also observed a significative trend to remission when AIDS was diagnosed at the time of KS diagnosis $(P=0.07)$. Nearly half of the patients developed KS while receiving HAART. This goes counter to the popular wisdom that patients on HAART rarely develop KS. These HAART-experienced patients developed KS at a time when their HIV viral load was poorly controlled $(n=61)$ and despite HIV suppression under the level of detection for only four patients. During the first 6 months, KS was in remission in $60.3 \%$ of 73 antiretroviral-naive patients, compared to $41.5 \%$ of 65 patients who were already receiving antiretroviral therapy at baseline. A highly significant relationship was found between KS remission and undetectable HIV plasma viral load during follow-up $(P=0.04$ at month $6, P \leqslant 0.0001$ at month 24 , $P=0.001$ at months 48 and 60 ) (Figure 1). This relationship was not observed for CD4 cell count (Figure 1). Multicentric Castleman's disease was associated with $\mathrm{KS}$ in five patients, and was associated with poor outcome $(P \leqslant 0.0001)$ : four patients had died, and one had progressed after 60 months of follow-up. In multivariate analysis only stage $\mathrm{S}$ remained significant: a stage So patient at baseline has 2.4 (CI 95\%: 1.2-5.0) more chance of KS remission during the first 6 months of follow-up than a stage S1 patient. The fact of being antiretroviral naive did not remain significant $(P=0.07)$ in the multivariate analysis.
Table 2 Risk factors for remission at 6 months according to baseline characteristics: univariate and multivariate analysis

\begin{tabular}{|c|c|c|c|c|c|}
\hline \multirow[b]{3}{*}{$\begin{array}{l}\text { Risk factor (no. of } \\
\text { patients) }\end{array}$} & \multicolumn{5}{|c|}{ Remission $(n=7 I)$} \\
\hline & \multicolumn{3}{|c|}{ Univariate analysis } & \multicolumn{2}{|c|}{$\begin{array}{l}\text { Multivariate } \\
\text { analysis }\end{array}$} \\
\hline & $\begin{array}{c}\text { No. of } \\
\text { patients }\end{array}$ & $\%$ & $P$ value ${ }^{a}$ & OR & $\mathrm{Cl} 95 \%$ \\
\hline \multicolumn{6}{|l|}{ Age (years) } \\
\hline$\leqslant 44(7 \mid)$ & 34 & 47.9 & 0.39 & & \\
\hline$>44(67)$ & 37 & 55.2 & & & \\
\hline \multicolumn{6}{|l|}{ Sex } \\
\hline Men (135) & 70 & 51.9 & 0.52 & & \\
\hline Women (3) & 1 & 33.3 & & & \\
\hline \multicolumn{6}{|l|}{ HIV exposure group } \\
\hline Homosexual ( $|0|$ ) & 52 & 51.5 & $0.37^{\mathrm{b}}$ & & \\
\hline Heterosexual (33) & 19 & 57.6 & & & \\
\hline $\begin{array}{l}\text { Intravenous drug } \\
\text { user (4) }\end{array}$ & 0 & 0 & & & \\
\hline \multicolumn{6}{|l|}{$\begin{array}{l}\text { HHV-8 endemic country of } \\
\text { origin }\end{array}$} \\
\hline Yes $(4 I)$ & 20 & 48.8 & 0.68 & & \\
\hline No (97) & 51 & 52.6 & & & \\
\hline \multirow{2}{*}{\multicolumn{6}{|c|}{$\begin{array}{l}\text { Opportunistic infection at } \\
\text { KS diagnosis }\end{array}$}} \\
\hline & & & & & \\
\hline Yes (37) & 17 & 45.9 & 0.43 & & \\
\hline No $(10 \mid)$ & 54 & 53.5 & & & \\
\hline \multicolumn{6}{|l|}{ AIDS revelated by KS } \\
\hline Yes (43) & 27 & 62.8 & 0.07 & & \\
\hline No (95) & 44 & 46.3 & & & \\
\hline \multicolumn{6}{|l|}{$\begin{array}{l}\text { Antiretroviral naive at } \\
\text { baseline }\end{array}$} \\
\hline Yes (73) & 44 & 60.3 & 0.03 & & \\
\hline No (65) & 27 & 41.5 & & & \\
\hline \multicolumn{6}{|l|}{ T stage } \\
\hline TO (79) & 45 & 57 & 0.13 & & \\
\hline TI (59) & 26 & 44.1 & & & \\
\hline \multicolumn{6}{|l|}{ I stage } \\
\hline $10(37)$ & 21 & 56.8 & 0.45 & & \\
\hline $11(101)$ & 50 & 49.5 & & & \\
\hline \multicolumn{6}{|l|}{ S stage } \\
\hline So (49) & 32 & 65.3 & 0.02 & 2.4 & {$[1.2-5.0]$} \\
\hline SI (89) & 39 & 43.8 & & I $\left(\right.$ reff $\left.^{c}\right)$ & \\
\hline \multicolumn{6}{|l|}{ CD4 cell counts } \\
\hline$<200 \mathrm{~mm}^{-3}(100)$ & 50 & 50 & 0.58 & & \\
\hline$\geqslant 200 \mathrm{~mm}^{-3}(38)$ & 21 & 55.3 & & & \\
\hline \multicolumn{6}{|l|}{ HIV-I plasma viral load } \\
\hline$\leqslant 200$ copies ml ${ }^{-1}(5)$ & 3 & 60 & 0.83 & & \\
\hline$>200$ copies mll $^{-1}(96)$ & 53 & 55.2 & & & \\
\hline
\end{tabular}

${ }^{\text {a } D e t e r m i n e d ~ w i t h ~} \chi^{2}$ Pearson (Fisher's exact test for 'sex'). 'W Without including IDU 'Reference.

The 73 patients who were antiretroviral naive at baseline remained on the same HAART regimen for at least 24 months. Fifty-four patients were treated with PI-containing regimens and 19 did not received PI. At baseline, the ACTG stage distribution ( $P=0.46$ for stage T, $P=0.7$ for stage $S$ and $P=0.47$ for stage $\mathrm{I})$, CD4 cell counts (median $55 \mathrm{~mm}^{-3}$ for non-PI group vs $76 \mathrm{~mm}^{-3}$ 
M6: $P>0.05$

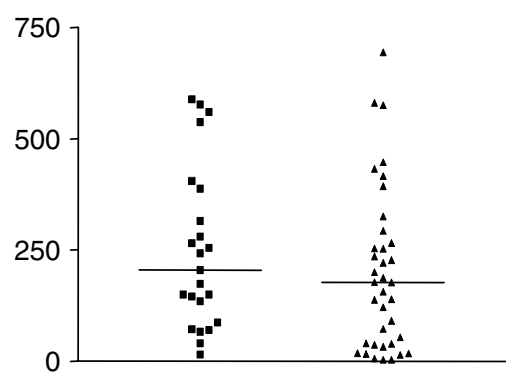

M6: $P=0.04$

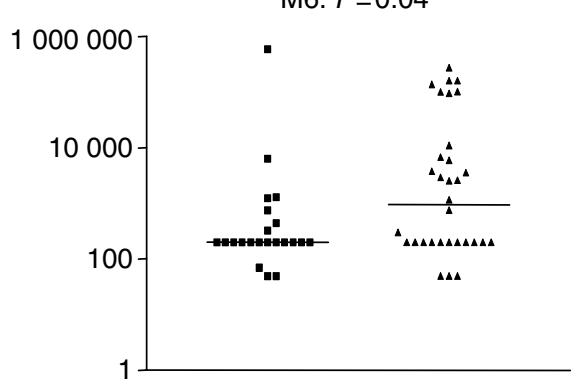

M24: $P>0.05$
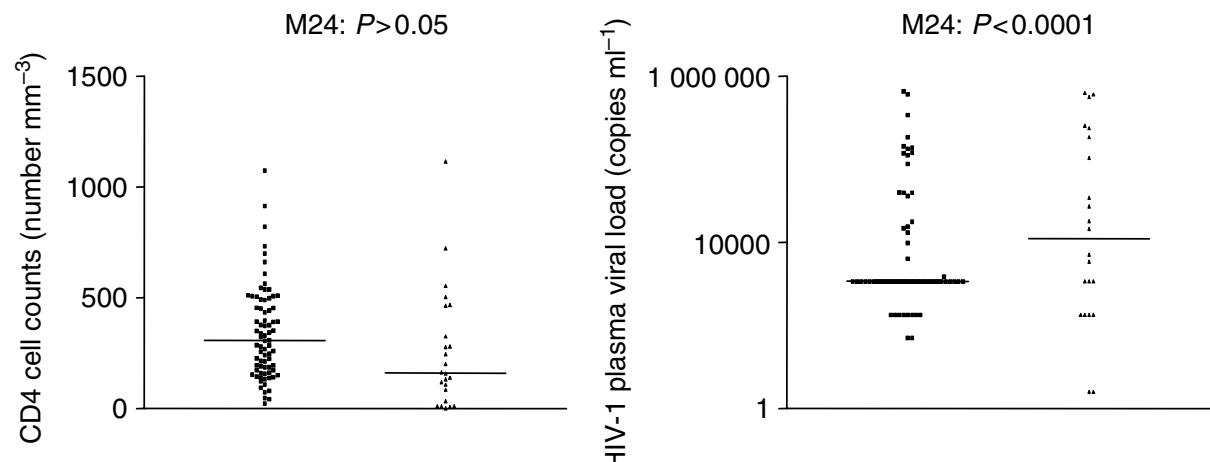

M60: $P>0.05$

M60: $P=0.001$
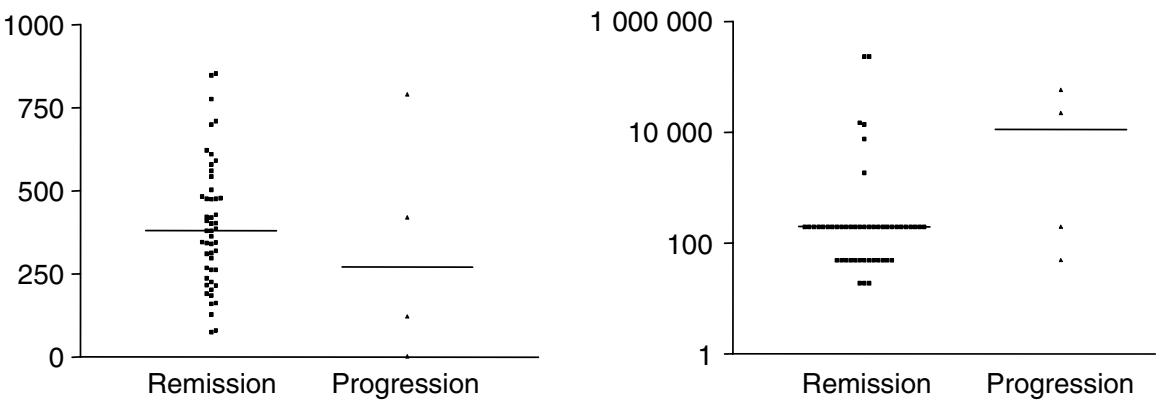

Figure I Comparison of HIV plasma viral load and CD4 cell counts between patients with KS remission and progression at months 6, 24 and 60 of follow-up. A logarithmic scale is used for HIV plasma viral load. Horizontal bars represent the medians and many points are at the lower limits of detection of the assay used.

for PI group), and HIV plasma viral load (median 204000 copies $\mathrm{ml}^{-1}$ for non-PI group $v s 275000$ copies $\mathrm{ml}^{-1}$ for PI group) were not statistically different between the two groups $(P=0.2$ and 0.1 for CD4 cell counts and viral load, respectively) and were not significantly related to KS remission at 6 months. During the 24 months of follow-up, the KS remission rate was not significantly different between the two groups (Figure 2): there was no evidence for a better outcome in the patients receiving a PI-containing regimen (Figure 2).

\section{DISCUSSION}

We examined clinical and biological factors associated with KS remission in HIV-1-infected patients receiving HAART. In multivariate analysis, only ACTG KS stage S0 was associated with KS remission at month 6 . Intercurrent multicentric Castleman's disease was associated with poor vital outcome and with KS progression. Undetectable HIV-1 plasma viral load was the best predictor of KS remission, independently of the CD4 cell count.

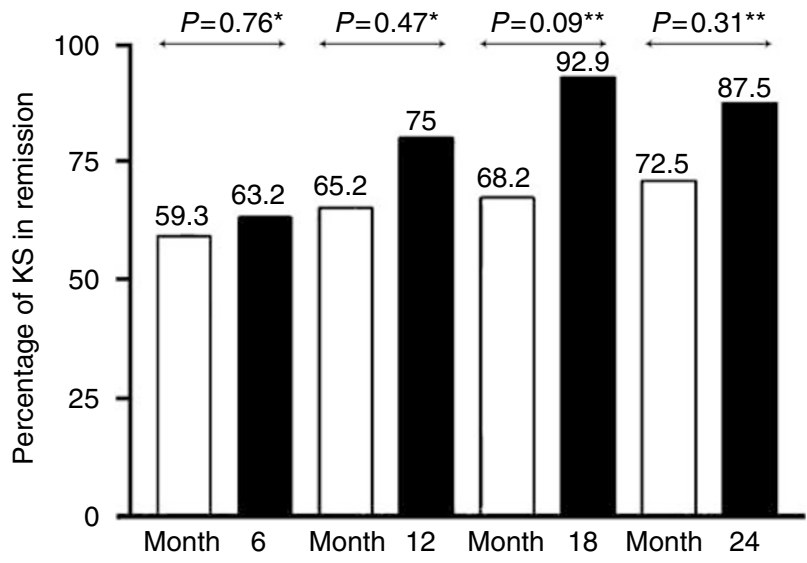

Figure 2 Efficacy of Pl-based regimens (white box) and non-Pl-based regimens (black box) on KS in $73 \mathrm{HIV}$-infected antiretroviral-naive patients. Efficacy was evaluated every 6 months for 24 months. * $\chi^{2}$ test and **Fisher's exact test. 
In our study, specific chemotherapy in addition to HAART had no impact on KS outcome. Finally, among patients who were antiretroviral naive at baseline, KS outcome was similar in those who received PI- and non-PI-based regimens.

HIV-1 interacts strongly with HHV-8. The HIV Tat protein, which is released by infected cells, regulates many viral and host functions. It stimulates the growth of KS lesions by stimulating the proliferation of spindle cells, activating cytokine genes (e.g. IL-6) and inhibiting IFN- $\gamma$-mediated apoptosis (Boshoff et al, 1995; Nicholas et al, 1997; Deregibus et al, 2002). The Tat gene has a direct angiogenic effect by interacting with several receptors, and also enhances HHV-8 infectivity (Albini et al, 1995; Aoki and Tosato, 2004). Uncontrolled HIV replication is associated with progression of HHV-8 malignancies (Nicholas et al, 1997; Brodt et al, 1998). As in previous studies, we found that suppression of HIV replication was crucial for controlling KS (Albini et al, 1995; Boshoff et al, 1995; Nicholas et al, 1997; Barillari and Ensoli, 2002; Deregibus et al, 2002).

The influence of the CD4 cell count on KS outcome is controversial. Two studies have shown a correlation between KS remission and a high CD4 cell count or a strong increase in the CD4 cell count. Dupont et al (2000) found that an increase in the CD4 cell count of more than $150 \times 10^{6} 1^{-1}$ after 12 months of HAART was predictive of complete remission from KS at month 24 in HIV-infected patients. Similarly, Cattelan et al (1999) found a positive correlation between the CD4 cell count and KS control during antiretroviral therapy. In contrast, like us, Nasti et al (2003a, b) found that HIV suppression was associated with good KS outcomes, independently of immune restoration reflected by the CD4 cell count. Undetectable HIV-1 plasma viral load thus appears to be the best predictor of KS remission, independently of the CD4 cell count.

In our subgroup of patients who had not previously received antiretroviral drugs, PI-based regimens and PI-sparing regimens were similarly effective in terms of KS remission. Protease inhibitors can affect important cellular processes such as angiogenesis, tumor growth and invasion, inflammation, antigen processing and presentation, cell survival, tissue remodelling and metastasis (Sgadari et al, 2003). Protease inhibitors have direct antiproliferative and antiangiogenic effects in vitro, and inhibit the development of KS-like lesions in animal models by blocking an enzyme required for the production of infectious HHV-8 particles (Pati et al, 2002; Sgadari et al, 2002, 2003). In clinical trials, PI-containing regimens led to full remission from $\mathrm{KS}$ in approximately $50 \%$ of patients, and conferred an added survival benefit (Burdick et al, 1997; Aboulafia, 1998; Krischer et al, 1998; Cattelan et al, 1999; De Milito et al, 1999; Paparizos et al, 2002; Leitch et al, 2003; Sgadari et al, 2003).

In contrast, the impact of NNRTI-based regimens on KS is controversial (Murdaca et al, 2002; Bani-Sadr et al, 2003; Portsmouth et al, 2003). Both complete remissions with NNRTI and relapses of KS in patients switching from PI- to NNRTI-based regimens have been described (Murdaca et al, 2002; Bani-Sadr et al, 2003). Two prospective studies showed that PI were not essential to clear HHV-8 DNA (Gill et al, 2002; Bourboulia et al, 2004). Similarly, Stebbing et al (2004) showed that NNRTI-based HAART regimens were not inferior to PI-based regimens in

\section{REFERENCES}

Aboulafia DM (1998) Regression of acquired immunodeficiency syndromerelated pulmonary Kaposi's sarcoma after highly active antiretroviral therapy. Mayo Clin Proc 73: 439-443

Albini A, Barillari G, Benelli R, Gallo RC, Ensoli B (1995) Angiogenic properties of human immunodeficiency virus type 1 Tat protein. Proc Natl Acad Sci USA 92: 4838-4842

Aoki Y, Tosato G (2004) HIV-1 Tat enhances Kaposi sarcoma-associated herpesvirus (KSHV) infectivity. Blood 104: 810-814 preventing KS. NNRTI-containing antiretroviral regimens are as effective as PI-based regimens on HIV infection, but are associated with better adherence, fewer adverse effects, and similar immune restoration (Bucher et al, 2003; Pozniak et al, 2003). However, PI-containing regimens are superior to NNRTI combinations including nevirapine or delavirdine in patients with advanced immunodepression and previous exposure to NRTI (Yazdanpanah et al, 2004). Our results, together with previous reports, suggest that $\mathrm{KS}$ regression in this setting is mediated by an overall improvement in immune function, modulation of cytokine expression, and control of HIV and HHV-8 replication, rather than by a direct specific antiangiogenic effect of antiretroviral therapy. It is noteworthy that the effects of NRTI and NNRTI on angiogenesis and proliferation have not been studied. However, we found that PI-sparing regimens were as effective as PI-based regimens in term of KS outcome in antiretroviral-naive HIVinfected patients.

Our patients who were antiretroviral naive at baseline had an increased chance of KS remission during the first 6 months of HAART in the univariate analysis. This might be due to partial recovery of anti-HHV-8 immune function, probable infection by wild-type HIV strains and a presumed better adherence compared to previously HAART-treated patients. Nevertheless, paradoxical transient deterioration have been described in KS patients, as seen in patients with tuberculosis and other opportunistic infections (Narita et al, 1998; Baril et al, 2000; Stone et al, 2002). Shelburne et al (2005) showed that patients who have been antiretroviral naive at time of diagnosis of their opportunistic infection have an increased risk of immune inflammatory syndrome. Also, Bourboulia et al (2004) reported that anti-HHV-8 immune reconstitution only occurred after more than 24 months of HAART, and that this contributed to the fall in the KS incidence during antiretroviral treatment. Early KS progression (within the first months following HAART introduction) may thus mimic immune reconstitution (Bower et al, 2005).

In conclusion, patients with ACTG KS stage S0 at baseline have an increased chance of remission of HHV-8 malignancies during the first six months of HAART. Patients with both KS and multicentric Castleman's disease have a particularly poor prognosis. Suppression of HIV replication by HAART appears to be the key factor in KS control, independently of the CD4 cell count. NNRTI- and NRTI-based regimens appear to be equivalent to PIbased regimens in terms of clinical and virological outcome in antiretroviral-naive HIV-infected patients with KS. It thus seems necessary to define more precisely, in clinical trials, the interest of specific anti-KS drugs on the evolution of KS in HAART era whereas PI- and NNRTI-based regimen seem to have similar efficiency on KS outcome.

\section{ACKNOWLEDGEMENTS}

The authors have no commercial links or other associations that might pose a conflict of interest (e.g. pharmaceutical stock ownership, consultancy, advisory board membership, relevant patents, or research funding). Statement naming sources of financial support (including grant numbers): None.
Bani-Sadr F, Fournier S, Molina JM (2003) Relapse of Kaposi's sarcoma in HIV-infected patients switching from a protease inhibitor to a nonnucleoside reverse transcriptase inhibitor-based highly active antiretroviral therapy regimen. AIDS 17: $1580-1581$

Baril L, Jouan M, Agher R, Cambau E, Caumes E, Bricaire F, Katlama C (2000) Impact of highly active antiretroviral therapy on onset of Mycobacterium avium complex infection and cytomegalovirus disease in patients with AIDS. AIDS 14: 2593-2596 
Barillari G, Ensoli B (2002) Angiogenic effects of extracellular human immunodeficiency virus type 1 Tat protein and its role in the pathogenesis of AIDS-associated Kaposi's sarcoma. Clin Microbiol Rev 15: $310-326$

Boshoff C, Schulz TF, Kennedy MM, Graham AK, Fisher C, Thomas A, McGee JO, Weiss RA, O’Leary JJ (1995) Kaposi's sarcoma-associated herpesvirus infects endothelial and spindle cells. Nat Med 1: 1274-1278 Bourboulia D, Aldam D, Lagos D, Allen E, Williams I, Cornforth D, Copas A, Boshoff C (2004) Short- and long-term effects of highly active antiretroviral therapy on Kaposi sarcoma-associated herpesvirus immune responses and viraemia. AIDS 18: $485-493$

Bower M, Fox P, Fife K, Gill J, Nelson M, Gazzard B (1999) Highly active anti-retroviral therapy (HAART) prolongs time to treatment failure in Kaposi's sarcoma. AIDS 13: 2105-2111

Bower M, Nelson M, Young AM, Thirwell C, Newsom-Davis T, Mandalia S, Dhillon T, Holmes P, Gazzard BG, Stebbing J (2005) J Clin Oncol 23: $5224-5228$

Brodt HR, Kamps BS, Gute P, Knupp B, Staszewski S, Helm EB (1997) Changing incidence of AIDS-defining illnesses in the era of antiretroviral combination therapy. AIDS 11: 1731-1738

Brodt HR, Kamps BS, Helm EB, Schofer H, Mitrou P (1998) Kaposi's sarcoma in HIV infection: impact on opportunistic infections and survival. AIDS 12: 1475-1481

Bucher HC, Kofler A, Nuesch R, Young J, Battegay M, Opravil M (2003) Meta-analysis of randomized controlled trials of simplified versus continued protease inhibitor-based antiretroviral therapy in HIV-1infected patients. AIDS 17: 2451-2459

Burdick AE, Carmichael C, Rady PL, Tyring SK, Badiavas E (1997) Resolution of Kaposi's sarcoma associated with undetectable level of human herpesvirus 8 DNA in a patient with AIDS after protease inhibitor therapy. J Am Acad Dermatol 37: 648-649

Cattelan AM, Calabro ML, Aversa SM, Zanchetta M, Meneghetti F, De Rossi A, Chieco-Bianchi L (1999) Regression of AIDS-related Kaposi's sarcoma following antiretroviral therapy with protease inhibitors: biological correlates of clinical outcome. Eur J Cancer 35: 1809-1815

Cattelan AM, Calabro ML, Gasperini P, Aversa SM, Zanchetta M, Meneghetti F, De Rossi A, Chieco-Bianchi L (2001) Acquired immunodeficiency syndrome-related Kaposi's sarcoma regression after highly active antiretroviral therapy: biologic correlates of clinical outcome. J Natl Cancer Inst Monogr 28: 44-49

De Milito A, Catucci M, Venturi G, Romano L, Incandela L, Valensin PE, Zazzi M (1999) Antiretroviral therapy with protease inhibitors in human immunodeficiency virus type 1- and human herpesvirus 8-coinfected patients. J Med Virol 57: 140-144

Deregibus MC, Cantaluppi V, Doublier S, Brizzi MF, Deambrosis I, Albini A, Camussi G (2002) HIV-1-Tat protein activates phosphatidylinositol 3kinase/AKT-dependent survival pathways in Kaposi's sarcoma cells. J Biol Chem 277: 25195-25202

Dupin N, Fisher C, Kellam P, Ariad S, Tulliez M, Franck N, Van Marck E, Salmon D, Gorin I, Escande JP, Weiss RA, Alitalo K, Boshoff C (1999) Distribution of human herpesvirus-8 latently infected cells in Kaposi's sarcoma, multicentric Castleman's disease, and primary effusion lymphoma. Proc Natl Acad Sci USA 96: 4546-4551

Dupont C, Vasseur E, Beauchet A, Aegerter P, Berthe H, de Truchis P, Zucman D, Rouveix E, Saiag P (2000) Long-term efficacy on Kaposi's sarcoma of highly active antiretroviral therapy in a cohort of HIVpositive patients. CISIH 92. Centre d'information et de soins de l'immunodeficience humaine. AIDS 14: 987-993

Gill J, Bourboulia D, Wilkinson J, Hayes P, Cope A, Marcelin AG, Calvez V, Gotch F, Boshoff C, Gazzard B (2002) Prospective study of the effects of antiretroviral therapy on Kaposi sarcoma - associated herpesvirus infection in patients with and without Kaposi sarcoma. J Acquir Immune Defic Syndr 31: 384-390

Krischer J, Rutschmann O, Hirschel B, Vollenweider-Roten S, Saurat JH, Pechere M (1998) Regression of Kaposi's sarcoma during therapy with HIV-1 protease inhibitors: a prospective pilot study. J Am Acad Dermatol 38: $594-598$

Krown SE, Testa MA, Huang J (1997) AIDS-related Kaposi's sarcoma: prospective validation of the AIDS Clinical Trials Group staging classification. AIDS Clinical Trials Group Oncology Committee. J Clin Oncol 15: $3085-3092$

Lebbe C, Blum L, Pellet C, Blanchard G, Verola O, Morel P, Danne O, Calvo F (1998) Clinical and biological impact of antiretroviral therapy with protease inhibitors on HIV-related Kaposi's sarcoma. AIDS 12: F45-F49
Leitch H, Trudeau M, Routy JP (2003) Effect of protease inhibitor-based highly active antiretroviral therapy on survival in HIV-associated advanced Kaposi's sarcoma patients treated with chemotherapy. HIV Clin Trials 4: 107-114

Levine AM, Tulpule A (2001) Clinical aspects and management of AIDSrelated Kaposi's sarcoma. Eur J Cancer 37: 1288-1295

Li TS, Tubiana R, Katlama C, Calvez V, Ait Mohand H, Autran B (1998) Long-lasting recovery in CD4 T-cell function and viral-load reduction after highly active antiretroviral therapy in advanced HIV-1 disease. Lancet 351: $1682-1686$

Murdaca G, Campelli A, Setti M, Indiveri F, Puppo F (2002) Complete remission of AIDS/Kaposi's sarcoma after treatment with a combination of two nucleoside reverse transcriptase inhibitors and one non-nucleoside reverse transcriptase inhibitor. AIDS 16: 304-305

Narita M, Ashkin D, Hollender ES, Pitchenik AE (1998) Paradoxical worsening of tuberculosis following antiretroviral therapy in patients with AIDS. Am J Respir Crit Care Med 158: 157-161

Nasti G, Talamini R, Antinori A, Martellotta F, Jacchetti G, Chiodo F, Ballardini G, Stoppini L, Di Perri G, Mena M, Tavio M, Vaccher E, D’Arminio Monforte A, Tirelli U (2003a) AIDS-related Kaposi's Sarcoma: evaluation of potential new prognostic factors and assessment of the AIDS Clinical Trial Group Staging System in the Haart Era - the Italian Cooperative Group on AIDS and Tumors and the Italian Cohort of Patients Naive From Antiretrovirals. J Clin Oncol 21: $2876-2882$

Nasti G, Talamini R, Antinori A, Martellotta F, Jacchetti G, Chiodo F, Ballardini G, Stoppini L, Di Perri G, Mena M, Tavio M, Vaccher E, D'Arminio Monforte A, Tirelli U (2003b) Kaposi sarcoma and its changing course in HIV infection AIDS-related Kaposi's Sarcoma: evaluation of potential new prognostic factors and assessment of the AIDS Clinical Trial Group Staging System in the Haart Era - the Italian Cooperative Group on AIDS and Tumors and the Italian Cohort of Patients Naive From Antiretrovirals. AIDS Read 13: 470, $475-476,479$

Nicholas J, Ruvolo VR, Burns WH, Sandford G, Wan X, Ciufo D, Hendrickson SB, Guo HG, Hayward GS, Reitz MS (1997) Kaposi's sarcoma-associated human herpesvirus- 8 encodes homologues of macrophage inflammatory protein-1 and interleukin-6. Nat Med 3: 287-292

Palella Jr FJ, Delaney KM, Moorman AC, Loveless MO, Fuhrer J, Satten GA, Aschman DJ, Hollberg SD (1998) Declining morbidity and mortality among patients with advanced human immunodeficiency virus infection. HIV Outpatient Study Investigators. N Engl J Med 338: 853-860

Paparizos VA, Kyriakis KP, Papastamopoulos V, Hadjivassiliou M, Stavrianeas NG (2002) Response of AIDS-associated Kaposi sarcoma to highly active antiretroviral therapy alone. J Acquir Immune Defic Syndr 30: $257-258$

Pati S, Pelser CB, Dufraine J, Bryant JL, Reitz Jr MS, Weichold FF (2002) Antitumorigenic effects of HIV protease inhibitor ritonavir: inhibition of Kaposi sarcoma. Blood 99: 3771-3779

Portsmouth S, Stebbing J, Gill J, Mandalia S, Bower M, Nelson M, Bower M, Gazzard B (2003) A comparison of regimens based on non-nucleoside reverse transcriptase inhibitors or protease inhibitors in preventing Kaposi's sarcoma. AIDS 17: F17-F22

Pozniak A, Gazzard B, Anderson J, Babiker A, Churchill D, Collins S, Fisher M, Johnson M, Khoo S, Leen C, Loveday C, Moyle G, Nelson M, Peter B, Wilkins E, Williams I, Youle M (2003) British HIV Association (BHIVA) guidelines for the treatment of HIV-infected adults with antiretroviral therapy. HIV Med 4(Suppl 1): 1-41

Sgadari C, Barillari G, Toschi E, Carlei D, Bacigalupo I, Baccarini S, Palladino C, Leone P, Bugarini R, Malavasi L, Cafaro A, Falchi M, Valdembri D, Rezza G, Bussolino F, Monini P, Ensoli P (2002) HIV protease inhibitors are potent anti-angiogenic molecules and promote regression of Kaposi sarcoma. Nat Med 8: 225-232

Sgadari C, Monini P, Barillari G, Ensoli B (2003) Use of HIV protease inhibitors to block Kaposi's sarcoma and tumour growth. Lancet Oncol 4: $537-547$

Shelburne SA, Visnegarwala F, Darcourt J, Graviss EA, Giordano TP, White Jr AC, Hamill RJ (2005) Incidence and risk factors for immune reconstitution inflammatory syndrome during highly active antiretroviral therapy. AIDS 19: 399-406

Stebbing J, Portsmouth S, Nelson M, Mandalia S, Kandil H, Alexander N, Davies L, Brock C, Bower M, Gazzard B (2004) The efficacy of ritonavir in the prevention of AIDS-related Kaposi's sarcoma. Int J Cancer 108: $631-633$ 
Stone SF, Price P, Tay-Kearney ML, French MA (2002) Cytomegalovirus (CMV) retinitis immune restoration disease occurs during highly active antiretroviral therapy-induced restoration of CMV-specific immune responses within a predominant Th2 cytokine environment. J Infect Dis 185: 1813 - 1817

Yazdanpanah Y, Sissoko D, Egger M, Mouton Y, Zwahlen M, Chene G (2004) Clinical efficacy of antiretroviral combination therapy based on protease inhibitors or non-nucleoside analogue reverse transcriptase inhibitors: indirect comparison of controlled trials. BMJ 328: 249 